\title{
A!
}

This is an electronic reprint of the original article.

This reprint may differ from the original in pagination and typographic detail.

Kumar, Deepak; Lehtonen, M.; Millar, R. J.

\section{Bolstering the Structure of Stand-alone Microgrids through Demand Side Management}

Published in:

2019 IEEE PES GTD Grand International Conference and Exposition Asia, GTD Asia 2019

DOI:

10.1109/GTDAsia.2019.8715855

Published: 15/05/2019

Document Version

Peer reviewed version

Please cite the original version:

Kumar, D., Lehtonen, M., \& Millar, R. J. (2019). Bolstering the Structure of Stand-alone Microgrids through Demand Side Management. In 2019 IEEE PES GTD Grand International Conference and Exposition Asia, GTD Asia 2019 (pp. 108-113). [8715855] IEEE. https://doi.org/10.1109/GTDAsia.2019.8715855

This material is protected by copyright and other intellectual property rights, and duplication or sale of all or part of any of the repository collections is not permitted, except that material may be duplicated by you for your research use or educational purposes in electronic or print form. You must obtain permission for any other use. Electronic or print copies may not be offered, whether for sale or otherwise to anyone who is not an authorised user. 
(C) 2019 IEEE. This is the author's version of an article that has been published by IEEE. Personal use of this material is permitted. Permission from IEEE must be obtained for all other uses, in any current or future media, including reprinting/republishing this material for advertising or promotional purposes, creating new collective works, for resale or redistribution to servers or lists, or reuse of any copyrighted component of this work in other works. 


\title{
Bolstering the Structure of Stand-alone Microgrids through Demand Side Management
}

\author{
Deepak Kumar, M. Lehtonen, R. J. Millar, Member, IEEE \\ Department of Electrical Engineering, Aalto University, Espoo, Finland \\ (deepakme2k9@gmail.com, matti.lehtonen@,aalto.fi )
}

\begin{abstract}
A stand-alone microgrid is subject to the challenges of inconsistent voltage and frequency. The transition of voltage and frequency from their predetermined range leads to a disparity in the value of active and reactive power. This paper addresses the voltage customization of a microgrid network to preserve power and to enable the mechanism of demand side management (DSM). An outer voltage and inner current loop have been adopted to perform DSM actions. An adaptive control structure is proposed that sets the voltage and current of the microgrid according to the modified voltage in the droop characteristics. The paper aims to address solutions to potential power catastrophes in the new era. A dynamic frequency controller is utilized to maintain the frequency in the predetermined range. The adequacy of the control structure is proved using simulation results performed in the MATLAB environment.
\end{abstract}

Keywords - Droop characteristics, Demand side management, Frequency control, Microgrid, Voltage control

\section{INTRODUCTION}

A burgeoning power crisis is placing immense pressure on conventional sources of energy and the need to eliminate coal-based products exacerbates the problem. There is a great urgency to propel research towards developing innovative technology that can fulfill the rising demand of electrical energy in the entire world, which will have to be met with carbon-neutral generation. The technology of the microgrid can become a significant part of the solution to the problem. It is a discrete energy management system that includes distributed energy sources, such as PV arrays, wind energy and fuel cells, and provides the benefit of a storage mechanism of electrical energy in case of power outage or for independent operation of the microgrid structure. A microgrid acts as a small version of the conventional power grid and it is a boon to the whole electrical structure, as it can run parallel with the grid or it is competent to run independently without the support of the grid network. It can provide affordable and reliable energy security for the urban and rural masses. To the extent that microgrids facilitate the integration of renewable energy sources in the power system, they will facilitate the reduction of greenhouse gas emissions and alleviate stress on transmission and distribution systems to a large extent. The emerging microgrid technology was introduced by the Consortium for Electric Reliability Technology Solutions (CERTS) in the year 1998, and is recognized as cutting-edge technology in the endeavor to quench the thirst of high demand of electrical energy in the world.

The control of microgrids plays a vital role in their deployment [1]. The voltage and frequency parameters of a grid-tied microgrid are controlled largely by the giant bus structure of the grid. The real challenges faced by an independent microgrid network occur when it is being disconnected from the grid. The objective of this paper is to control the microgrid through proportional control, i.e., with droop control [2] - [5]. A frequency control scheme is presented for an islanded microgrid with the establishment of energy management on the consumption side [6]. Variation in frequency is caused by a change in active power demand. The power handling capability and stability of a microgrid are compromised by changes in voltage and frequency. Therefore, an optimal control strategy has been developed to coordinate different kinds of distributed generation in an autonomous microgrid, and also maintains the power of the overall microgrid in the case of deviation in frequency and voltage parameters [7]. There is a high dependency of active power on voltage in the case of a resistive microgrid and accordingly the control scheme is developed to regulate the active power in [8]. The term demand side management (DSM) was coined in 1980 by the Electric Power Research Institute (EPRI). The approach towards DSM is carried out by a well-known method, conservative voltage reduction (CVR), which is prevalent in grid-connected microgrids [9]. Independent microgrids can become the solution for rural communities where there is no access to the grid, hence the consolidation of demand side management with voltage customization has received a lot of research attention. Despite having certainty of power sharing in a microgrid network, the study in [10] does not consider the voltage-current droop scheme when performing DSM, which has been considered in [11]. The benefits and challenges of demand side management is extensively discussed in [12] and the UK electricity system has been considered in its list of advantages. The concept of conservative voltage reduction is established for saving of energy and reducation of power consumption by incorporating close loop voltage mitigation algorithm. Primarily it was focused on grid connected system; however the concept is extended for islanded mode of operation [13]-[16].

The paper is organized as follows: Section II concisely explains the control structure of an autonomous microgrid 


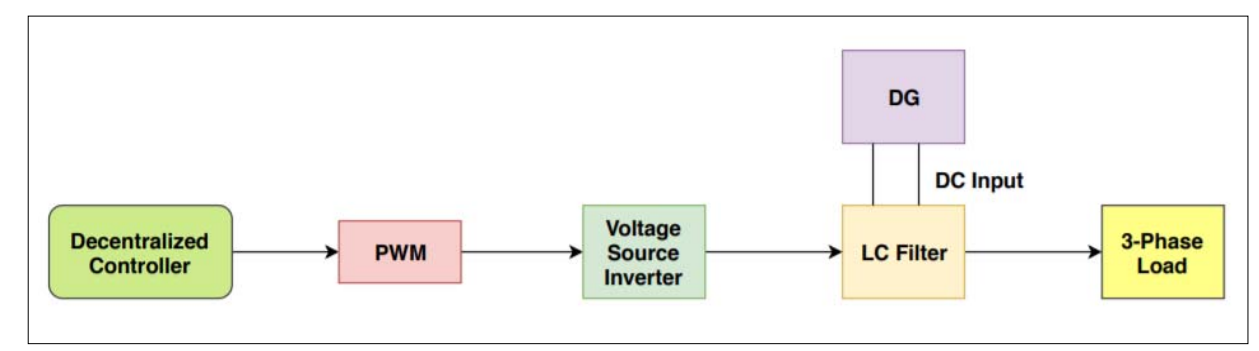

Fig. 1. Microgrid architecture

network, and incorporates estimation of the droop constant, an outer loop for voltage control, an inner loop for current control and a frequency control mechanism. Section III presents the voltage customization algorithm, and briefly discusses Demand Side Management (DSM) and its implementation in the independent microgrid network. Section IV presents the DSM application in the MATLAB environment and convincing results are shown to prove the efficacy of the proposed controller. Finally, Section V encapsulates the proposed work with concluding remarks.

\section{CONTROL DESIGN OF INDEPENDENT MICROGRID NETWORK}

A sophisticated control arrangement is requited to preserve the voltage and frequency of the independent microgrid structure. The paper presents decentralized control of microgrid through adequate control mechanism shown in Fig. 1.

The voltage control is dealt by the outer loop that constitutes a PI controller to lessen the difference between the estimated signal and actual output signal provided by a voltage source inverter. The frequency is controlled by a competent regulator and the output generated from the frequency control mechanism goes to each of the control blocks to synchronize the frequency. The objective of the paper is to discuss the DSM application of the microgrid network, which will lead to lower energy and power consumption, increasing the viability of future microgrids. The control structure designed to achieve the DSM application is shown in Fig. 4. The IEEE 1547 standards allow a lower voltage bound of $-10 \%$, and will help to establish a DSM mechanism in the microgrid structure.

\section{A. Estimation of Droop constant $\left(Z_{C}\right)$}

A voltage-current droop strategy is proposed in the paper to establish the Demand side management (DSM) capability of a microgrid. The estimation of the droop constant $\left(Z_{C}\right)$ is required to consider the voltage drop from the DG source to the downstream load on the consumption side. The proposed method utilizes the following equation:

$$
\mathrm{V}_{\mathrm{dr}}=0.9 * \text { Nominal voltage }+\mathrm{Z}_{\mathrm{C}} * \mathrm{I}_{\mathrm{RMS}}
$$

$\mathrm{V}_{\mathrm{dr}}$ is the voltage generated by the $\mathrm{v}-\mathrm{i}$ droop mechanism. Fig. 2 shows the estimation of the droop constant $Z_{C}$, and is computed by adding all the line impedances from the

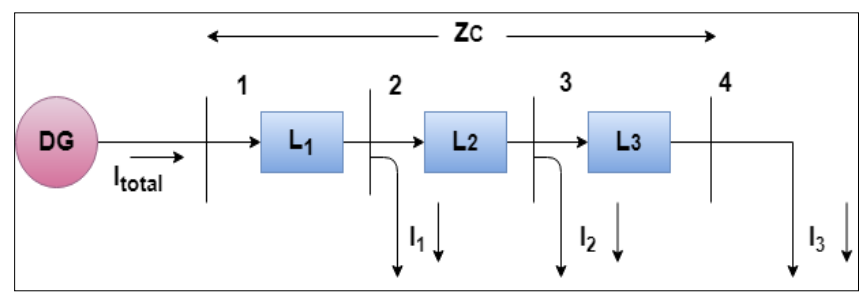

Fig. 2. Estimation of Droop constant

DG source connected at Bus 1 to the load $\mathrm{L}_{3}$ at bus 4 , i.e. loads $\mathrm{L}_{1}, \mathrm{~L}_{2}$ and $\mathrm{L}_{3}$. The allowable voltage lower bound of $10 \%$ is implemented by the expression $(0.9 *$ Nominal voltage) and the product of the droop constant $Z_{C}$ and the RMS current from the inverter establish the voltage $V_{d r}$ is fed to the voltage loop controller explained in next section.

\section{B. Outer loop for Voltage Control}

The voltage control incorporates two proportional-integral regulators that precisely scale down the difference between the $\mathrm{V}_{\mathrm{dr}}$ and $\mathrm{V}_{\mathrm{qr}}$ voltage signals, and provide current signals $i_{d r}$ and $i_{\text {qr }}$ to the current control loop shown in Fig 3. The computation carried out by the outer voltage loop is in the $\mathrm{d}-\mathrm{q}$ frame, as it is convenient to design a PI regulator with two signals. The following equations represent the control action:

$$
\begin{aligned}
& \mathrm{I}_{\mathrm{dr}}=\mathrm{K}_{\mathrm{p}}\left(\mathrm{V}_{\mathrm{dr}}-\mathrm{V}_{\mathrm{d}}\right)+\mathrm{K}_{\mathrm{i}} \int\left(\mathrm{V}_{\mathrm{dr}}-\mathrm{V}_{\mathrm{d}}\right) \mathrm{dt}-\mathrm{wC}_{\mathrm{f}} \mathrm{V}_{\mathrm{q}}+\mathrm{Hi}_{\mathrm{od}} \text { (2) } \\
& \mathrm{I}_{\mathrm{qr}}=\mathrm{K}_{\mathrm{p}}\left(\mathrm{V}_{\mathrm{qr}}-\mathrm{V}_{\mathrm{q}}\right)+\mathrm{K}_{\mathrm{i}} \int\left(\mathrm{V}_{\mathrm{qr}}-\mathrm{V}_{\mathrm{q}}\right) \mathrm{dt}+\mathrm{wC}_{\mathrm{f}} \mathrm{V}_{\mathrm{d}}+\mathrm{Hi}_{\mathrm{oq}}
\end{aligned}
$$

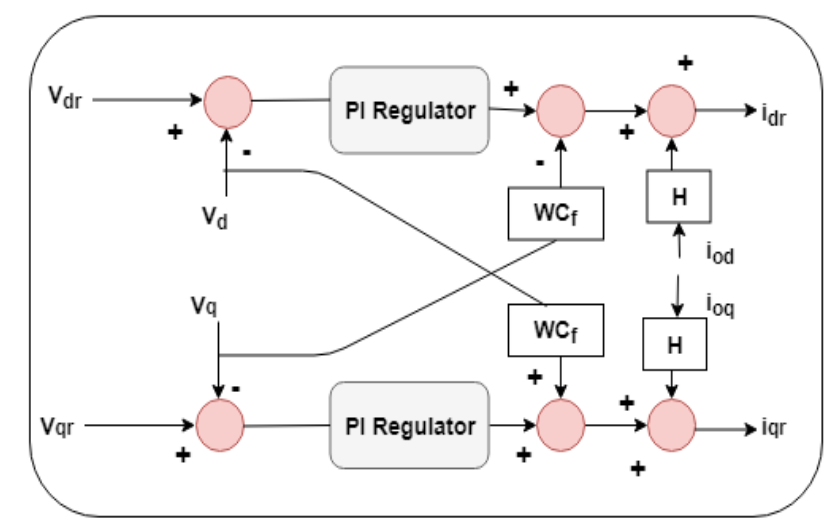

Fig. 3. Outer voltage control loop 


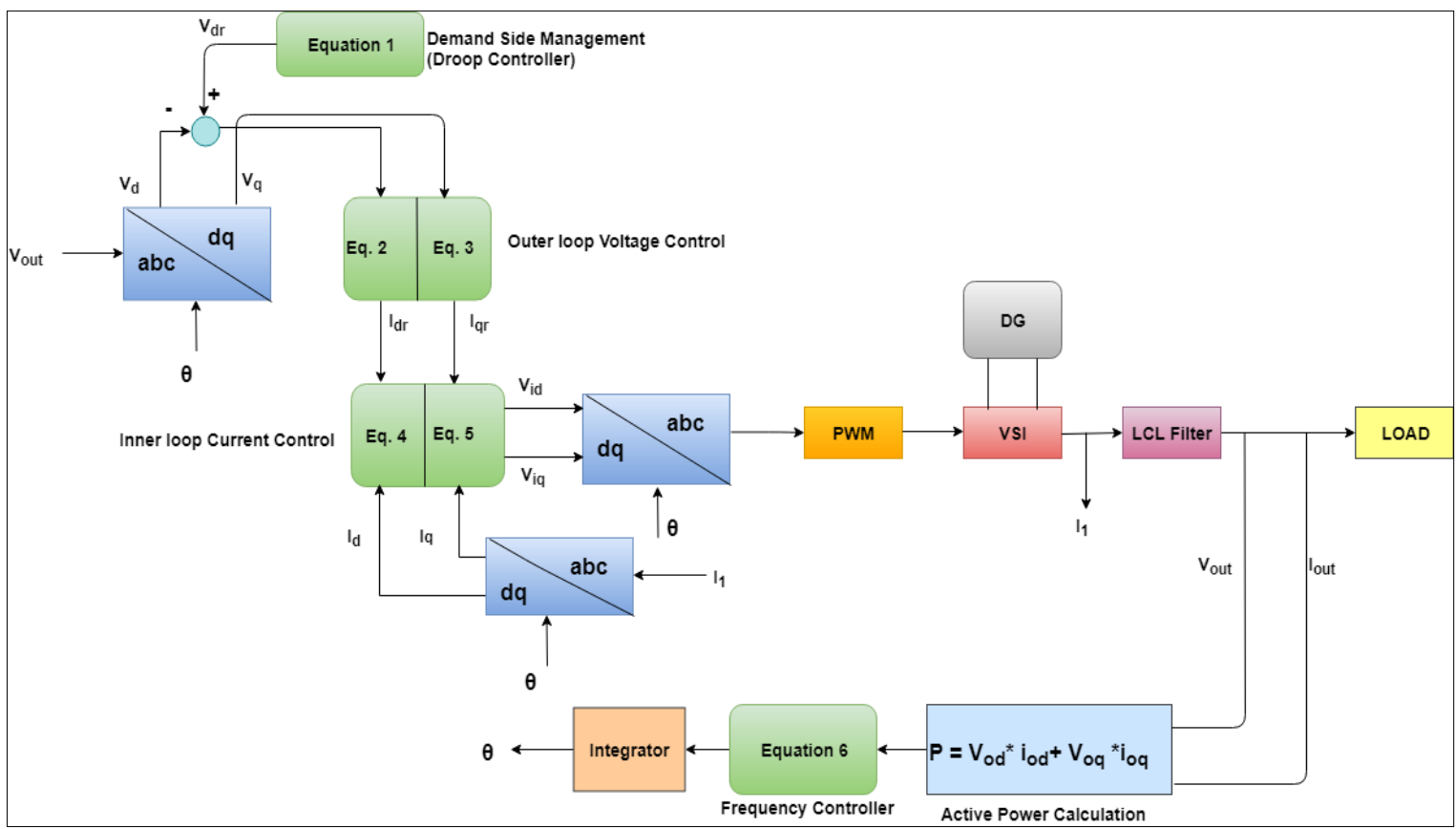

Fig. 4. Control mechanism of Microgrid network

In equations (2) and (3), $\mathrm{K}_{\mathrm{p}}$ and $\mathrm{K}_{\mathrm{i}}$ represent the controller parameters. $\mathrm{C}_{\mathrm{f}}$ refers to the filter capacitance, and constant $\mathrm{H}$, the feed-forward gain.

\section{Inner loop for Current control}

The consolidation of two PI regulator forms the inner current loop. The difference between the current signals $i_{d r}$ and $i_{q r}$ from the outer voltage loop and the signals obtained from the VSI in the $d-q$ frame are inputs to the proportional-integral controller used to imitate the current signal ( $\mathrm{I}_{1}$ in Fig. 4), as shown in Fig. 5. The resultant signals $\mathrm{V}_{\text {id }}$ and $\mathrm{V}_{\text {iq }}$ are obtained, and will be transformed to the a-b-c form for pulse width modulation. The following equation depicting the control mechanism:

$$
\begin{aligned}
& \mathrm{V}_{\mathrm{id}}=\mathrm{K}_{\mathrm{p}}\left(\mathrm{I}_{\mathrm{dr}}-\mathrm{I}_{\mathrm{d}}\right)+\mathrm{K}_{\mathrm{i}} \int\left(\mathrm{I}_{\mathrm{dr}}-\mathrm{I}_{\mathrm{d}}\right) \mathrm{dt}-\mathrm{wL}_{\mathrm{f}} \mathrm{I}_{\mathrm{q}} \\
& \mathrm{V}_{\mathrm{iq}}=\mathrm{K}_{\mathrm{p}}\left(\mathrm{I}_{\mathrm{qr}}-\mathrm{I}_{\mathrm{q}}\right)+\mathrm{K}_{\mathrm{i}} \int\left(\mathrm{I}_{\mathrm{qr}}-\mathrm{I}_{\mathrm{q}}\right) \mathrm{dt}+\mathrm{wL}_{\mathrm{f}} \mathrm{I}_{\mathrm{d}}
\end{aligned}
$$

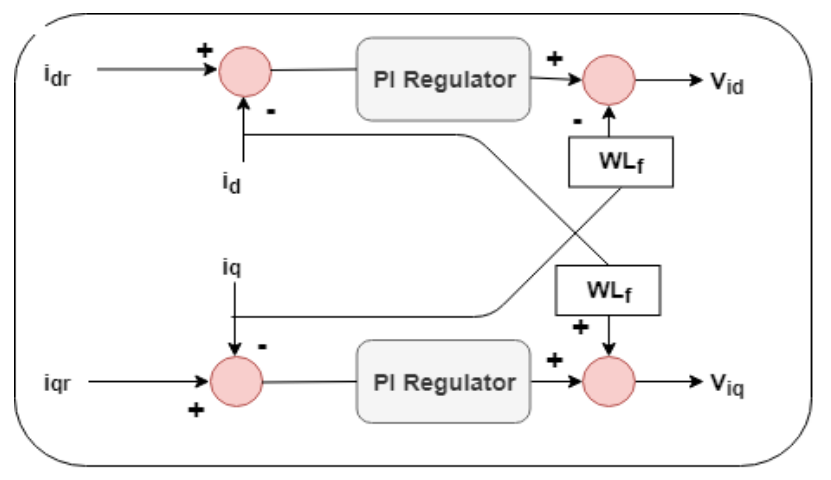

Fig. 5. Inner current control loop

$\mathrm{K}_{\mathrm{p}}$ and $\mathrm{K}_{\mathrm{i}}$ represent the controller parameters and constant $\mathrm{L}_{\mathrm{f}}$ is the filter inductance gain.

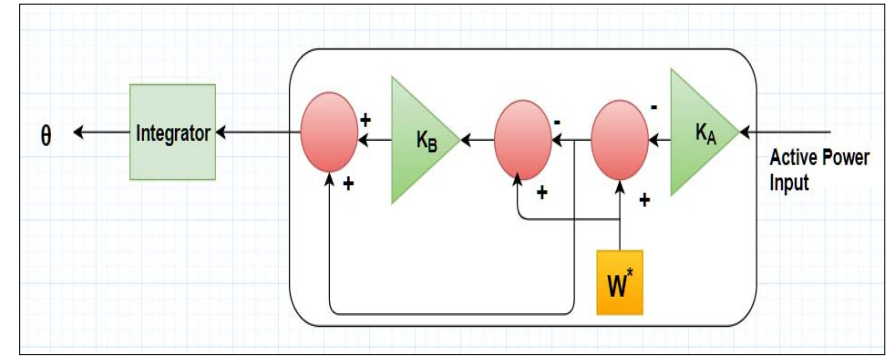

Fig. 6. Frequency control mechanism

\section{A. Control of Frequency}

The deviation in frequency is caused by irregular load and generation profiles. An enhanced frequency controller is proposed to adjust the generation and consumption of power in the microgrid network.

The frequency controller incorporates two gains $\mathrm{K}_{\mathrm{A}}$ and $\mathrm{K}_{\mathrm{B}}$, which dynamically control the varying frequency due to irregular demand at different instants of time, as shown in Fig. 6. The following equation depicts the frequency controller:

$$
\omega_{\mathrm{o}}=\mathrm{K}_{\mathrm{B}}\left[\omega^{*}-\left(\omega^{*}-\mathrm{PK} \mathrm{A}\right)\right]+\left(\omega^{*}-\mathrm{PK}_{\mathrm{A}}\right)
$$

$\mathrm{K}_{\mathrm{A}}$ and $\mathrm{K}_{\mathrm{B}}$ are the gains of the frequency controller and $\omega^{*}$ is the predetermined frequency to be controlled. The constant $\mathrm{P}$ denotes the active power.

\section{VOLTAGE CUSTOMIZATION ALGORITHM}

Conservative Voltage Reduction (CVR) is the control mechanism of customizing the voltage to lessen the consumption of energy. The IEEE 1547 standard allows the voltage to be reduced by $10 \%$ and this can be adopted 
to harness the DSM capability. Voltage curtailment on the demand side accomplishes the benefits of reduction in the consumption of energy $(\mathrm{kWh})$, active power $(\mathrm{kW})$ and reactive power (kVAR) of microgrid networks with predominantly impedance loads. Eq. (1) incorporates a voltage diminishing term $(0.9 *$ Nominal voltage $)$ and a product term of the droop constant and RMS current that tends to a produce resultant voltage always greater than the allowable lower-bound voltage. Hence, the consumer will always be supplied with sufficient voltage.

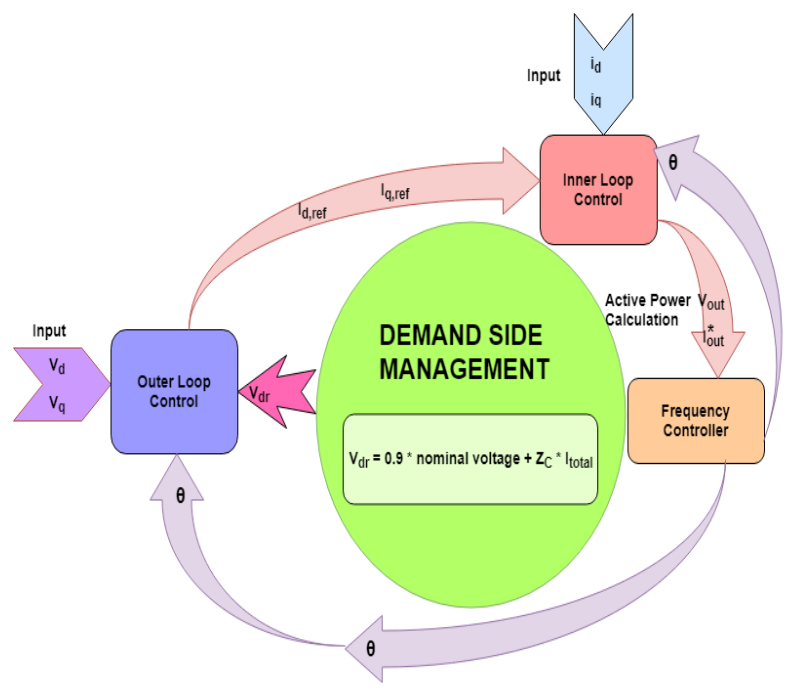

Fig. 7. DSM Algorithm

\section{Approach to Demand Side Management (DSM)}

The DSM algorithm shown in Fig. 7 has been established utilizing the aforementioned $\mathrm{v}-\mathrm{i}$ droop mechanism and equation (1). The relationship between power and voltage

$$
\begin{gathered}
\mathrm{P}=\mathrm{P}_{0}\left(\frac{V}{\mathrm{~W}_{\mathrm{I}}}\right)^{\alpha} \\
\mathrm{Q}=\mathrm{Q}_{0}\left(\frac{\mathrm{V}}{\mathrm{V}^{\mathrm{E}}}\right)^{\beta}
\end{gathered}
$$

The power consumption at the rated voltage $\mathrm{V}_{0}$ is defined by Po and Qo. $\alpha$ and $\beta$ represents the exponents of power and is variable in nature against different types of load demand. It is observed that reducing the voltage by $10 \%$ in (7) and (8) accomplishes a saving of $19 \%$ in the reactive and active powers for $\alpha=\beta=2$. Hence the effectiveness of DSM is enhanced by making use of the $10 \%$ lower voltage allowed by the IEEE 1547 standard and can be observed in the results.

\section{RESULTS AND DISCUSSION}

The outer voltage and inner current control were introduced to regulate the voltage and current of the microgrid network shown in Fig. 4. The output from the voltage source inverter (VSI) is fed back to the inner and outer loops through the abc-dq transformation block that converts three phase axes into two phase signals. The proportional-integral controller in each of the outer and inner loops imitates the current signal $i_{1}$ in Fig. 4, and adapts to the voltage signal established by the $\mathrm{v}-\mathrm{i}$ droop characteristics. The desired lowering of the voltage is achieved through the outer voltage and inner current control mechanism. Frequency synchronization is achieved through the Phase Locked Loop (PLL) block in MATLAB Simulink. The ' $\theta$ ' generated from the frequency controller is fed to each of the abc-dq transformation blocks to provide a check on the frequency. The frequency controller efficiently handles the frequency in the case of voltage adjustment via the droop mechanism.

The proposed method has been simulated in the MATLAB framework. The voltage has been intentionally reduced by $10 \%$ and a substantial reduction in energy and power is shown through simulation results.

\section{A. Establishment of DSM algorithm:}

The customized voltage signal (nominal voltage reduced by $10 \%$ ) with consideration of voltage drop across the line has been provided to the droop controller and the resultant signal is sent to the outer loop that controls voltage. The outer voltage loop adapts to the voltage signal and the PI regulator tries to imitate the voltage fed to the droop controller to carry out the DSM. Further, the current signal is generated by the outer loop, and is given to the inner current loop to produce a current in proportion to the customized voltage. The DSM strategy is demonstrated in the simulation results of voltage, current, frequency and power.

The frequency of the overall microgrid is shown in Fig. 8. With the introduction of DSM, it is observed that the frequency controller maintains the frequency in the predetermined range shown in Fig. 8. Hence, the control mechanism is efficaciously preserving the frequency.

The voltage reduction of $10 \%$ can be observed in Figs. 9 and 10 . It is interesting to note that the resultant voltage established by the droop controller is always greater than the customized voltage, as it considers the voltage drop across the line expressed in (1). The voltage difference with and without the establishment of DSM strategy can be noted in Fig. 10. The currents can be observed in Fig. 11. There is a substantial reduction in power demand, with active power reduced by $22.2 \%$ and reactive power scaled down by $24.3 \%$ with the implementation of the DSM mechanism, as can be observed in Figs. 12 and 13. The introduction of the DSM strategy maintains the power of the microgrid structure in the range of $75 \%-80$ $\%$. The reduction in energy consumption benefits other consumers in peak hours and stress on the conventional grid will also be greatly reduced. 


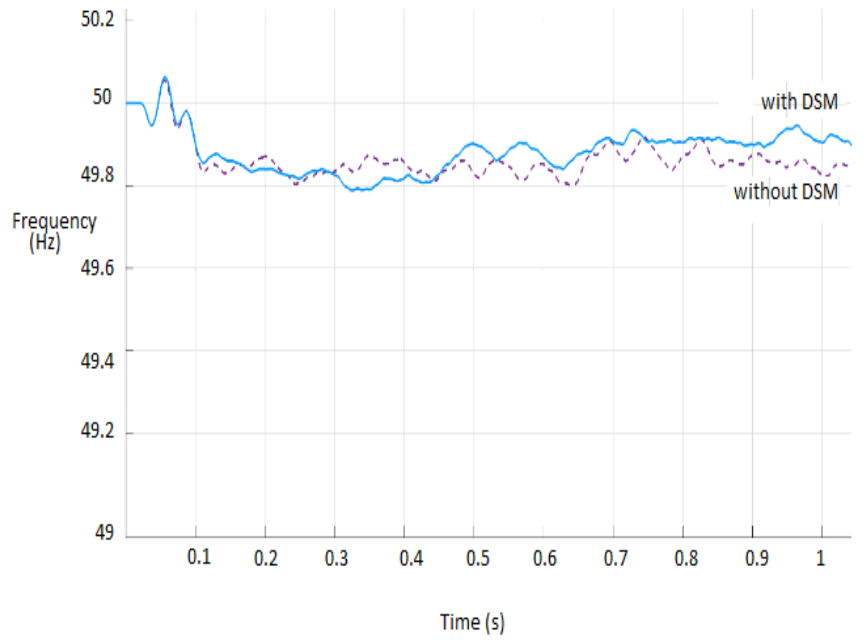

Fig. 8. Comparison of frequency with and without DSM

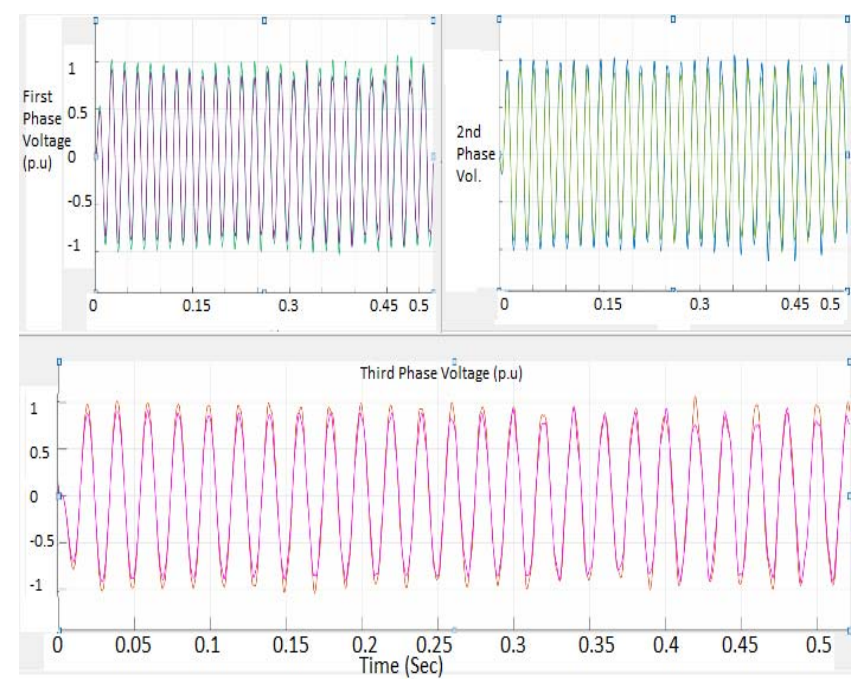

Fig. 9. Customization of voltage by $10 \%$

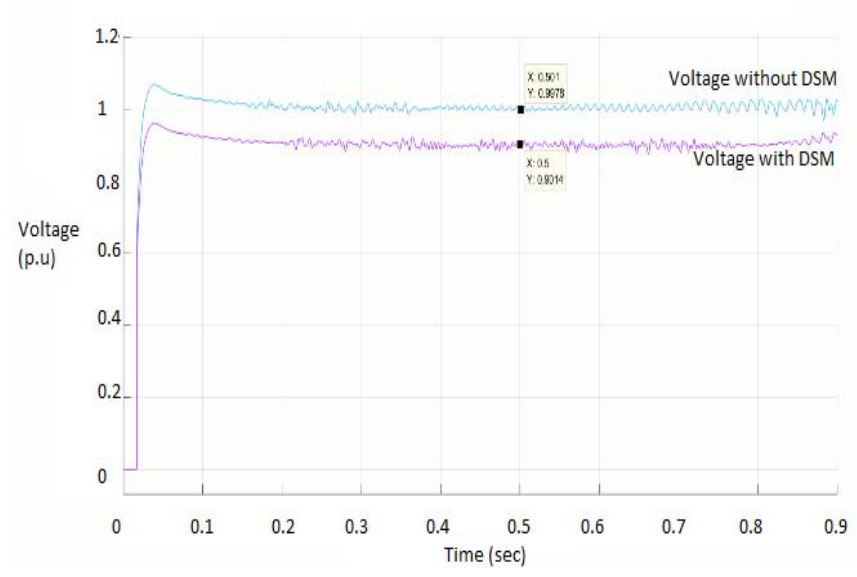

Fig. 10. Scenario of Voltage with and without DSM strategy

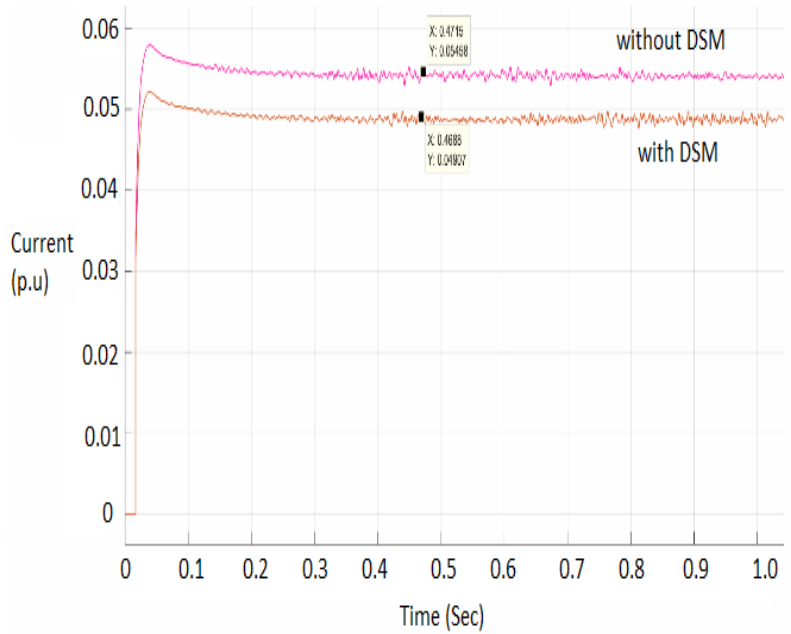

Fig. 11. Scenario of Current

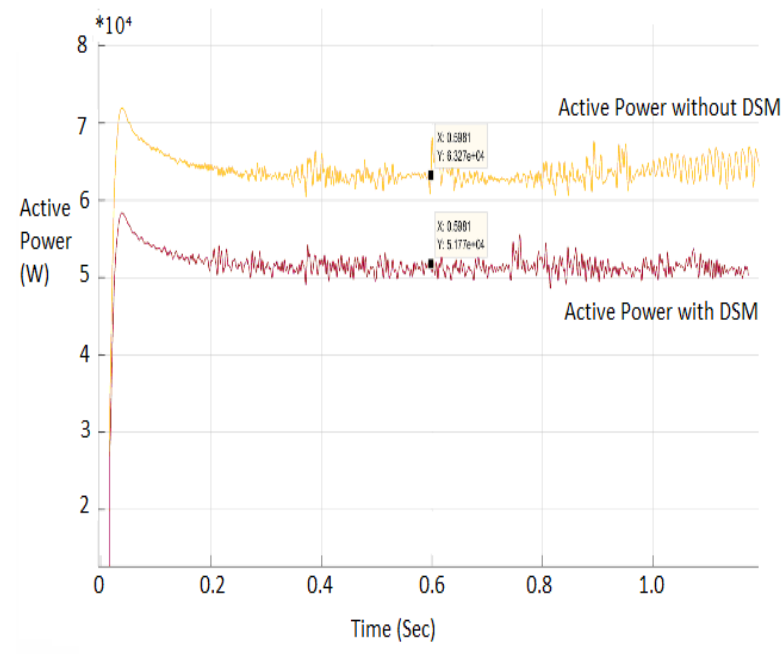

Fig. 12. Active Power Scenario

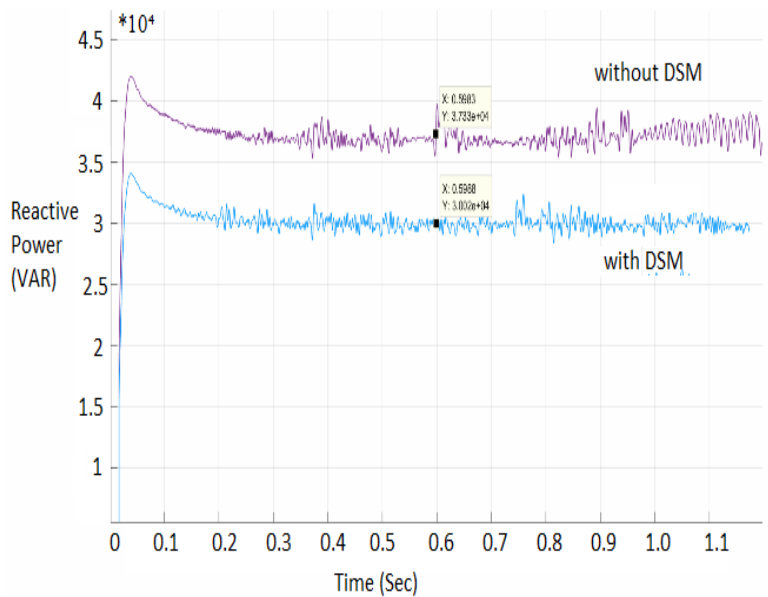

Fig. 13. Reactive Power Scenario 


\section{CONCLUSION}

Demand Side Management (DSM) has been successfully demonstrated through simulation results. The inner and outer loop control mechanisms adequately adapt to the established voltage signal in the droop control. The scaling down of voltage by $10 \%$ in the droop strategy can save $15 \%-25 \%$ of power for impedance loads, which may benefit other consumers and bolster the microgrid structure during peak hours. A stand-alone microgrid has the inherent challenge of low inertia and consequently, the frequency is easily disturbed. Hence, the proposed frequency control mechanism is competent enough to handle these types of situations, maintaining the frequency within a predetermined range when the distributed generation in a stand-alone microgrid has difficulty matching the demand, warranting the application of DSM within the microgrid.

\section{REFERENCES}

[1] H. Bevrani, M. Watanabe, Y. Mitani, "Microgrid controls" in Standard Handbook for Electrical Engeneers, New York: McGraw Hill, 2012.

[2] A. P. Lopes, C. Moreira, A. Madureira, "Defining control strategies for microgrids islanded operation", IEEE Transactions on Power Systems, vol. 21, pp. 916-924, 2006.

[3] P. Arboleya, D. Diaz, J. Guerrero, P. Garcia, F. Briz, C. Gonzalez-Moran, J. G. Aleixandre, "An improved control scheme based in droop characteristic for microgrid converters", Electric Power Systems Research, vol. 80, pp. 1215-1221, 2010.

[4] H. Moussa, A. Shahin, J. P. Martin, S. Pierfederici and N. Moubayed, "Optimal Angle Droop for Power Sharing Enhancement with Stability Improvement in Islanded Microgrids," in IEEE Transactions on Smart Grid.

[5] E.Barklund, N. Pogaku, M. Prodanovic, C. HernandezAramburo, T. C. Green, "Energy management in autonomous microgrid using stability-constrained droop control of inverters", IEEE Transactions on Power Electronics, vol. 23, pp. 2346-2352, 2008.

[6] S. Acharya, M. S. E. Moursi and A. Al-Hinai, "Coordinated Frequency Control Strategy for an Islanded Microgrid With Demand Side Management Capability," in IEEE Transactions on Energy Conversion, vol. 33, no. 2, pp. 639-651, June 2018.

[7] Y. Xu, H. Sun, W. Gu, Y. Xu and Z. Li, "Optimal Distributed Control for Secondary Frequency and Voltage Regulation in an Islanded Microgrid," in IEEE Transactions on Industrial Informatics.

[8] M. B. Delghavi, A. Yazdani, "An adaptive feedforward compensation for stability enhancement in droopcontrolled inverter-based microgrids", IEEE Transactions on Power Delivery, vol. 26, pp. 1764-1773, 2011.

[9] P. Palensky, D. Dietrich, "Demand Side Management: Demand Response Intelligent Energy Systems and Smart Loads", IEEE Trans. Industrial Informatics, vol. 7, no. 3, pp. 381-388, 2011.

[10] S. Rahman, Rinaldy, "An efficient load model for analyzing demand side management impacts", IEEE
Trans. Power Syst., vol. 8, no. 3, pp. 1219-1226, Aug. 1993.

[11] A. Mohsenian-Rad, V. Wong, J. Jatskevich, R. Schober, A. Leon-Garcia, "Autonomous demand-side management based on game-theoretic energy consumption scheduling for the future smart grid", IEEE Trans. Smart Grid, vol. 1, no. 3, pp. 320-331, Dec. 2010.

[12] G. Strbac, "Demand Side Management: Benefits and Challenges", Energy Policy, vol. 36, no. 12, pp. 44194426, 2008.

[13] P.Sen and K. Lee, "Condervation Voltage reduction technique: An application guideline for smarter grid," IEEE Trans. Industrial Appl., vol. 52, no. 3, pp. 21222128, May/Jun 2016.

[14] S. K. Jha, D. Kumar, I. Kamwa, "Smart demand response management of islanded microgrid using voltage-current droop mechanism", Intl. Journal of Emerging Electric Power Systems, vol. 19, no. 1, 2018.

[15] O. Leitermann, V. Martinalli, J.Simonelli, "Estimation of customer voltages for planning of conservative voltage reduction," in proc. 2015, IEEE Power Energy Soc. Gen. Meet., pp 1-5, July 2015.

[16] A. M. Pasha, H. H. Zeineldin, A. Saad Al-Sumaiti, M. S. El-Moursi, E. F. El Sadanny, "Conservative voltage reduction for autonomous microgrids based on V-I droop characteristics," IEEE Trans. Sustainable Energy, vol. 8, no. 3, pp. 1076-1085, July 2017. 